\title{
MID-LATITUDE AURORA IN SOLAR CYCLES 23-24 FROM OBSERVATIONS IN THE SOUTH OF EASTERN SIBERIA
}

\author{
A.V. Mikhalev \\ Institute of Solar-Terrestrial Physics SB RAS, \\ Irkutsk,Russia,mikhalev@iszf.irk.ru
}

\begin{abstract}
The paper presents observations of midlatitude aurora (MA) in the south of Eastern Siberia in solar cycles 23-24. Spectral composition and dominant emissions of MA, daily distribution of MA detection probability, dependence on the level of geomagnetic activity, and classification according to types of aurora are discussed. A close relationship is shown between the intensity of dominant emission at $630.0 \mathrm{~nm}$ and the Dst index during magnetic storms (MSs). It is pointed out that the most intense MA are recorded during MS main phases. The MA detected on November 20, 2003 can
\end{abstract}

enlarge the list of great aurora. For the severe MSs $\left(D s t_{\min }<-200 \mathrm{nT}\right)$ of March 24, 1991, April 6, 2000, October 30 and November 20, 2003, March 17, 2015, the observed dynamics of 557.7 and $630.0 \mathrm{~nm}$ auroral emissions is presented. Mechanisms of emission excitation during geomagnetic storms and a possible connection with magnetospheric structures are discussed.

Keywords: mid-latitude aurora, magnetic storms.

\section{INTRODUCTION}

Magnetic storms (MSs) are the most important geophysical phenomena of solar origin, which cause changes in characteristics of Earth's upper atmosphere and ionosphere. At middle latitudes, strong MSs occur with significant enhancements of the forbidden atomic oxygen line [OI] at $630.0 \mathrm{~nm}$ when this emission as a relatively weak component of the mid-latitude nightglow may increase tens of times or more for several hours. This leads to a phenomenon of mid-latitude aurora (MA). In the literature there is no generally accepted definition of MA. Some authors use the term "lowlatitude aurora" which is associated with auroral emissions observed at geomagnetic latitudes of $\leq 50^{\circ}$ during MSs. At the same time, other authors apply the term "mid-latitude aurora", using as features the peculiarities of mechanisms of enhancement of mid-latitude emissions during MSs, the presence of the $\mathrm{N}_{2}{ }^{+}$emission in the spectrum, and/or a large ratio of 630.0 and $557.7 \mathrm{~nm}$ [OI] emission intensities [Rassoul et al., 1993].

MA is believed to be a relatively rare geophysical phenomenon. According to [Krakovetsky et al., 1989], the probability of observation of MA and low-latitude aurora (LA) in the Northern Hemisphere for latitudes $55-60^{\circ} \mathrm{N}$ is five cases per year; for latitudes $50-55^{\circ}$, 1 case per year; for $40-50^{\circ}, 0.1$ cases per year; in the equatorial zone, 0.01 cases per year. Meanwhile, Shiokawa et al. [2005] believe that invisible (subvisual) MA occurs much more frequently.

When considering MA and LA, several mechanisms of emission excitation during MSs are identified. Among these mechanisms are precipitation of heavy particles (ions and neutral atoms) from the ring current, collisions with low-energy electron fluxes, etc. [Cole, 1970; Fishkova, Martsvaladze, 1985; Tinsley et al., 1986; Rassoul et al., 1993]. Rassoul et al. [1993] have identified MA and LA of several types. Heavy particles with $1-100 \mathrm{keV}$ energies precipitating from the ring current when recharged generate low-latitude (neutrals) and mid-latitude (ions) aurora at geomagnetic latitudes of $\leq 40^{\circ}$ and $\geq 40^{\circ}$ respectively. Electron fluxes with energies of $\leq 10 \mathrm{eV}$ cause such a phenomenon as SAR arc, and electron precipitation with energies $\sim 10-1000 \mathrm{eV}$ produce type «d» MA.

This paper presents some characteristics and features of MA derived from observations at ISTP SB RAS Geophysical Observatory $(\mathrm{GPhO})\left(52^{\circ} \mathrm{N}, 103 \mathrm{E}^{\circ}\right)$ in solar cycles 23-24. It presents more detailed data on MA than in [Mikhalev, 2013] acquired during strong and very strong MSs.

\section{EQUIPMENT AND OBSERVATIONAL METHOD}

This study is based on observations of 557.7 and $630.0 \mathrm{~nm}$ atomic oxygen emissions obtained at ISTP SB RAS GPhO with zenith photometers (1989-1993 and 1997-2010) and a patrol spectrometer with low spectral resolution as part of the ISP-51 spectrograph and CCD color matrix SONY ICX285AQ (2011-2018). Emission lines in the zenith photometers were found using tilting interference filters with a full width at half maximum of $\Delta \lambda_{1 / 2} \sim 1-2 \mathrm{~nm}$. The angular field of view in photometer channels was $\sim 4-5^{\circ}$. The absolute calibration of optical equipment was carried in individual periods from standard stars and was then controlled with calibrators - stabilized light sources. Characteristics of the spectrometer are presented at [http://atmos.iszf.irk.ru/ru/data/spectr]. Until 2012, the observations were made at night for 1-2 weeks before and after the new moon, and from April 2012 , every night. Since 2009, a color wide-angle camera has been used which is designed to study spatiotemporal variations in nightglow and to control atmospheric transmittance [http://atmos.iszf.irk.ru/ru/data/color]. In 2013, an all-sky camera KEO Sentinel recording spatial picture of the $630.0 \mathrm{~nm}$ emission was put into operation [http://atmos.iszf.irk.ru/ru/ data/keo]. 


\section{OBSERVATIONAL RESULTS AND DISCUSSION}

A number of studies have shown that one of the geomagnetic indices that has the highest correlation with the $630.0 \mathrm{~nm}$ emission intensity $\left(I_{630.0}\right)$ during MSs is the Dst index [Truttse, 1973; Rassoul et al., 1992; Lobzin, Pavlov, 1998; Mikhalev et al., 2004]. In this regard, MSs are classified in this work according to Dst. Gonzalez et al. [1999] have indicated that according to the Dst index storms are subdivided into moderate ($\left.100<D s t_{\min }<-50 \mathrm{nT}\right)$, intense $\left(-200<D s t_{\min }<-100 \mathrm{nT}\right)$, and extrastorms $\left(D s t_{\min }<-200 \mathrm{nT}\right)$. Variations of $I_{630.0}$ during moderate, intense MSs, and extrastorms from 1991 to 2012 from GPhO observations have been analyzed in [Mikhalev, 2013]. This paper deals only with intense MSs and extrastorms. Table lists some characteristics of MA and strong MSs, during which ISTP SB RAS GPhO made optical observations: $\Delta I_{630.0}$ denotes a maximum enhancement of the $630.0 \mathrm{~nm}$ emission relative to the background level of nightglow; the final column provides the time of recording of the highest intensity of this emission $I_{\max }$ during MS. Seven of $21 \mathrm{MSs}$ according to the classification [Gonzalez et al., 1999] can be assigned to extrastorms; and 14, to intense MSs. Virtually for all the MSs listed in Table, the greatest enhancement of the $630.0 \mathrm{~nm}$ emission $\left(I_{\max }\right)$ in MA occurs during MS main phases. An exception is the March 31, 2001 magnetic storm with maximum MA intensity observed during the recovery phase.

Figure 1 depicts the dynamics of the dominant 630.0 and $557.7 \mathrm{~nm}$ emissions for four extrastorms with different levels of night maximum Dst (inverted values): March 24, 1991, April 6, 2000 (Dst $t_{\max }$ 200-220 nT), and
October 30 and November 20, 2003 (Dst $\left.t_{\max } \sim 350-400 \mathrm{nT}\right)$.

Figure 2 shows variations in 630.0 and $557.7 \mathrm{~nm}$ emission intensities and Dst during the March 17, 2015 magnetic storm. The observational data presented in Figures 1 and 2 corresponds in time to the MS main phase. Noteworthy among the main features of the emission intensity variations is a significant excess of the $630.0 \mathrm{~nm}$ emission intensity over the $557.7 \mathrm{~nm}$ emission intensity (the large ratio $\left.I_{630.0} / I_{557.7}\right)$ during MS main phases at certain moments. Exceptions are the November 20, 2003 superstorm and March 31, 2001 MS (MS recovery phase) when at certain moments $I_{557.7}$ was higher than $I_{630.0}$. The second feature is the correlation of $I_{630.0}$ with inverted values of the Dst index during MS main phases. The exception is the March 17, 2015 MS (Figure 2).

Long-term regular observations of airglow at $\mathrm{GPhO}$ have established some features of 630.0 and $557.7 \mathrm{~nm}$ emission variations during MSs typical for middle latitudes of the Asian continent near the geomagnetic meridian of $177^{\circ}$ E. Bellow are characteristics and features of $630.0 \mathrm{~nm}$ emission variations during MSs and their discussion.

\section{Daily distribution of MA occurrence proba- bility during MSs}

The existence of daily variations in the occurrence probability of various forms of aurora is well-known (see, e.g., [Nadubovich, 1992]). In this case, variations in aurora occurrence frequency at different stations during the night differ considerably not only in amplitude but also in form. Early studies have indicated that among the main causes of the daily variation in aurora recording is a change in the position of the observation

Magnetic storms with MA

\begin{tabular}{|c|c|c|c|c|c|c|}
\hline No. & Date & $\begin{array}{l}K_{\mathrm{p} \max } \\
\text { for storm }\end{array}$ & $\begin{array}{c}D s t_{\min } \\
\text { for storm, } \mathrm{nT}\end{array}$ & $\begin{array}{c}D s t_{\min } \\
\text { for night, } \mathrm{nT}\end{array}$ & $\Delta I_{630.0}, \mathrm{kR}$ & $\begin{array}{l}\text { Time of recording } \\
\text { of } I_{\max },(\mathrm{UT}, \mathrm{hr})\end{array}$ \\
\hline 1 & 1991.03.24 & 9- & -288 & -225 & $\sim 2.6$ & $\sim 20.5$ \\
\hline 2 & 1999.01 .13 & $77_{0}$ & -112 & -112 & $\sim 0.04$ & $\sim 18$ \\
\hline 3 & 2000.04.06 & $8+$ & -288 & -220 & $\sim 2.8$ & $\sim 19.5$ \\
\hline 4 & 2000.10 .04 & $7+$ & -182 & -143 & $\sim 0.12$ & $\sim 17.5$ \\
\hline 5 & 2000.11 .06 & $7_{0}$ & -159 & -159 & $\sim 0.11$ & $\sim 18.5$ \\
\hline 6 & 2001.03 .20 & $7+$ & -149 & -149 & $\sim 0.05$ & $\sim 15.5$ \\
\hline 7 & 2001.03.31 & 9- & -387 & -284 & $\sim 3.5$ & $\sim 16$ \\
\hline 8 & 2001.10 .21 & $8-$ & -187 & -187 & $\sim 0.5$ & $\sim 20$ \\
\hline 9 & 2002.04 .17 & $7+$ & -124 & -98 & $\sim 0.075$ & $\sim 19.5$ \\
\hline 10 & 2003.10 .29 & $9_{0}$ & -350 & -281 & $\sim 2.5$ & $\sim 22.5$ \\
\hline 11 & 2003.10.30 & $9_{0}$ & -383 & -383 & $\sim 4$ & $\sim 22$ \\
\hline 12 & 2003.11.20 & 9- & -422 & -422 & $\sim 19.4$ & $\sim 20$ \\
\hline 13 & 2004.01 .22 & $7_{0}$ & -130 & -130 & $\sim 0.07$ & $\sim 14.5$ \\
\hline 14 & 2005.05 .08 & $8+$ & -110 & -110 & $\sim 0.1$ & $\sim 17$ \\
\hline 15 & 2011.09 .26 & $6+$ & -101 & -100 & $\begin{array}{l}\sim 0.4 \\
\sim\end{array}$ & $\begin{array}{ll}\sim 17 \\
\sim\end{array}$ \\
\hline 16 & 2012.10 .08 & $7-$ & -106 & -106 & $\sim 0.05$ & $\sim 17.5$ \\
\hline 17 & 2013.03 .17 & $7-$ & -132 & -132 & $\sim 0.1$ & $\sim 19$ \\
\hline 18 & 2015.03.17 & 8- & -222 & -187 & $\sim 14$ & $\sim 15.5$ \\
\hline 19 & 2015.10 .07 & $7+$ & -124 & -119 & $\sim 0.4$ & $\sim 17$ \\
\hline 20 & 2015.12 .20 & $7-$ & -155 & -155 & $\sim 0.45$ & $\sim 19$ \\
\hline 21 & 2016.10 .13 & $6+$ & -104 & -103 & $\sim 0.15$ & $\sim 21$ \\
\hline
\end{tabular}



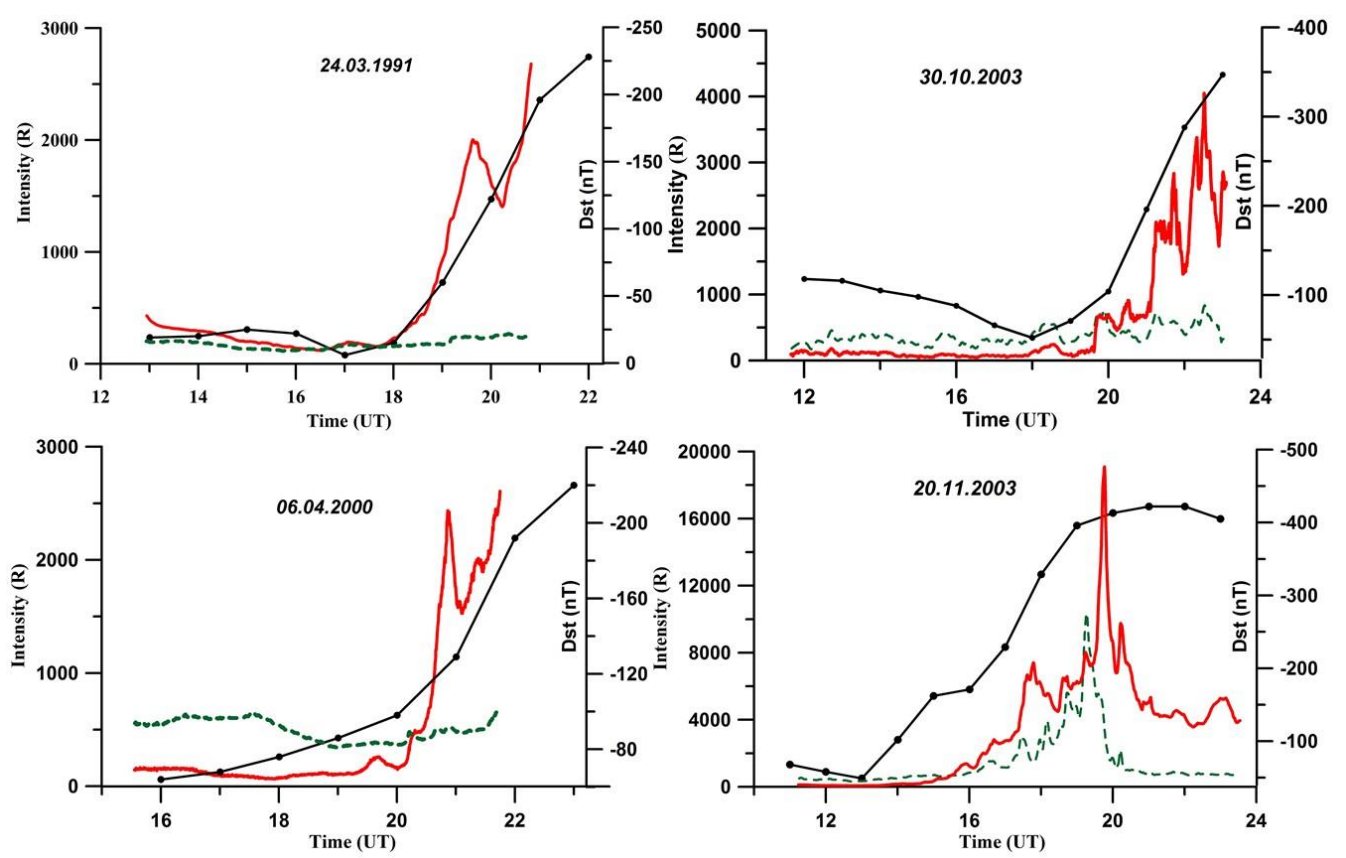

Figure 1. Variations in $630.0 \mathrm{~nm}$ (red line) and $557.7 \mathrm{~nm}$ (green line) emission intensities and Dst index (black line with circles) during magnetic storms classified, according to the classification [Gonzalez et al., 1999], as extrastorms, with maximum Dst throughout the night: 200-220 nT $(a) ; \sim 350-400 \mathrm{nT}(b)$

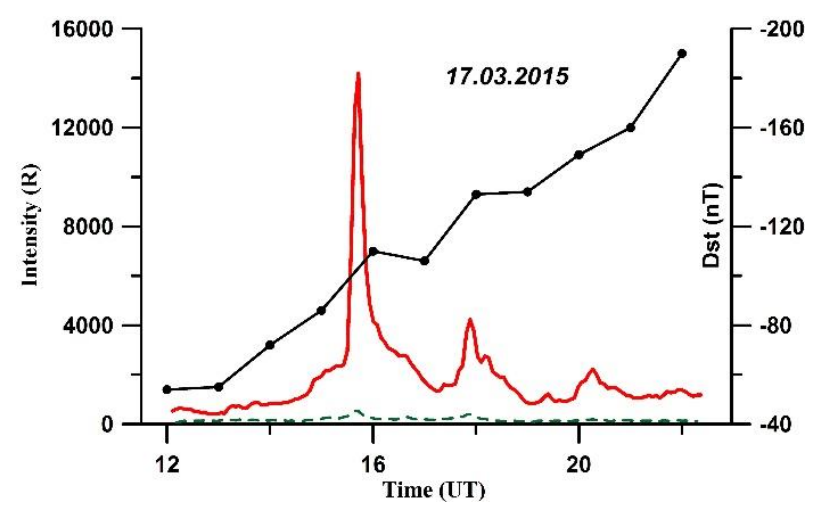

Figure 2. Variations in the 630.0 and $557.7 \mathrm{~nm}$ emission intensity and Dst during the March 17, 2015 magnetic storm. Notations are the same as in Figure 1

station relative to the auroral oval during the night. Figure 3, $a$ shows night distributions of maximum perturbations of $I_{630.0}$. Figure $3, b$ shows hourly averaged daily distributions of $D s t$ variations for geomagnetically disturbed days with $D s t \leq-50 \leq-200 \mathrm{nT}$ from January 1957 to April 2000 [Mikhalev, 2001]. Horizontal lines indicate nighttime intervals for winter and summer solstices available for nighttime optical observations at ISTP SB RAS GPhO.

Local midnight corresponds to 17 UT. Perturbations of $I_{630.0}$ in the MS main and initial phases are seen to be recorded predominantly in the second half of the night, whereas in the recovery phase, during evening hours before midnight. In view of the relationship between $I_{630.0}$ and $D s t$, data shown in Figure 3,b allowed us to suggest that there is a longitude dependence of MA and their forms [Mikhalev, 2001].

\section{Dependence on geomagnetic activity level}

Of certain interest is the dependence of $I_{630.0}$ at middle latitudes on the geomagnetic activity level. Figure 4 shows the dependence of maximum increase in the atomic oxygen red line intensity $\Delta I_{630.0}$ on the geomagnetic activity level (according to $D s t$ ) for MSs listed in Table. The interpolation line in Figure 4 is plotted regardless of the maximum intensity during the March 17, 2015 MS (square in Figure 4).

The resulting regression equation

$$
\lg \left(I_{630.0}\right)=-0.0167 \text { Dst-4.14 }
$$

agrees fairly well with the data obtained in [Mikhalev, 2013] and divided according to the MS main and recovery phases.

The $630.0 \mathrm{~nm}$ emission intensity in the MS main phase is significantly higher than that in the MS recovery phase [Mikhalev, 2013].

An exception is the March 31, 2001 MS when the 630.0 $\mathrm{nm}$ emission intensity in the recovery phase was as high as $~ 3.5 \mathrm{kR}$ [Degtyarev et al., 2003]. It has been found that coefficients in regression equations relating the $I$ 630.0 enhancement to Dst in the MS main and recovery phases have close values [Mikhalev, 2013].

\section{Relationship with variations of ionospheric parameters}

A relationship between the mid-latitude nightglow emission intensity and ionospheric parameters has been established in earlier studies (see, e.g., [Barbier, 1959]). In particular, it has been found that $I_{630.0}$ variations correlate fairly well with variations in F2-region parameters: height $h^{\prime} \mathrm{F} 2$ and critical frequency $f_{\mathrm{o}} \mathrm{F} 2$ (electron density). This holds for weak and moderate geomagnetic disturbances when the main mechanism of $630.0 \mathrm{~nm}$ emission excitation in nightglow is dissociative recombination. $\mathrm{GPhO}$ has recorded $630.0 \mathrm{~nm}$ emission variations of this type during geomagnetic disturbances many times. In 

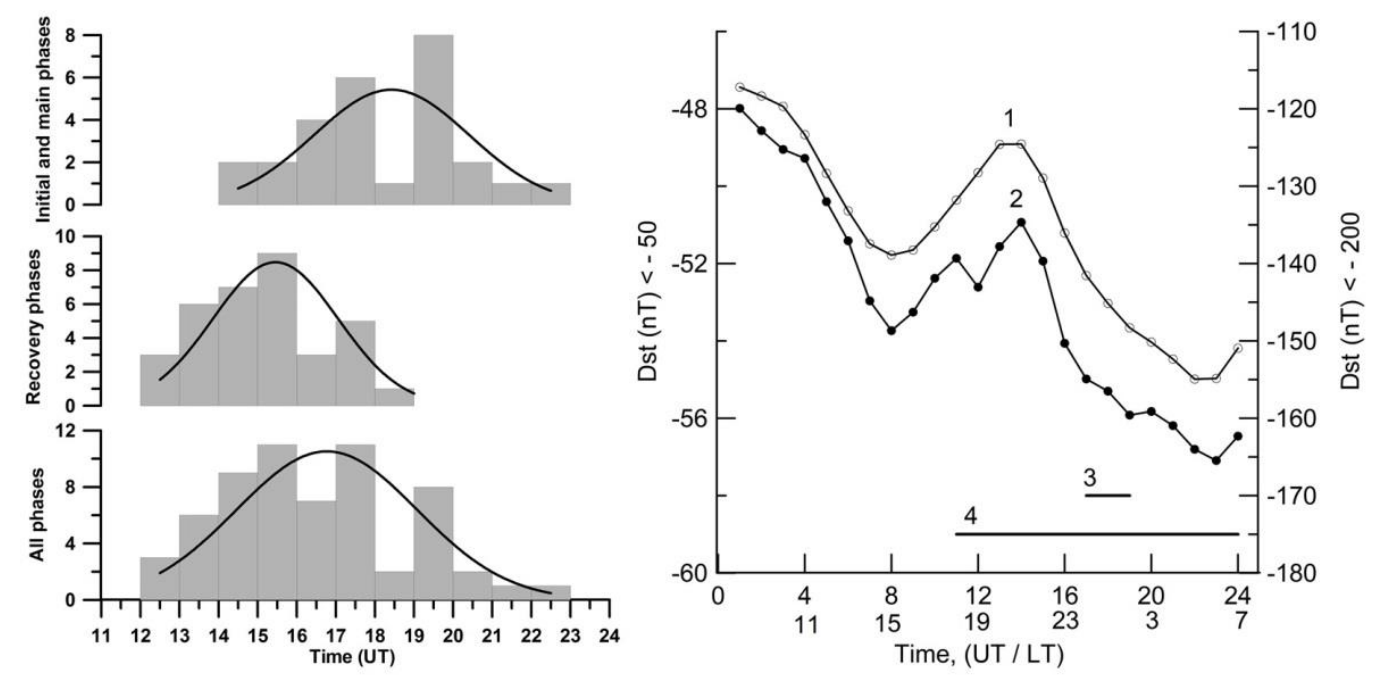

Figure 3. Daily (night) distributions of maximum perturbations of the $630.0 \mathrm{~nm}$ emission intensity during MSs (a). Daily distribution of Dst [Mikhalev, 2001] (b): curves 1 and 2 respectively - on geomagnetically disturbed days with $D s t \leq-50$ and $-200 \mathrm{nT}$; lines 3 and 4 - in nighttime intervals at ISTP SB RAS GPhO for summer and winter solstices respectively

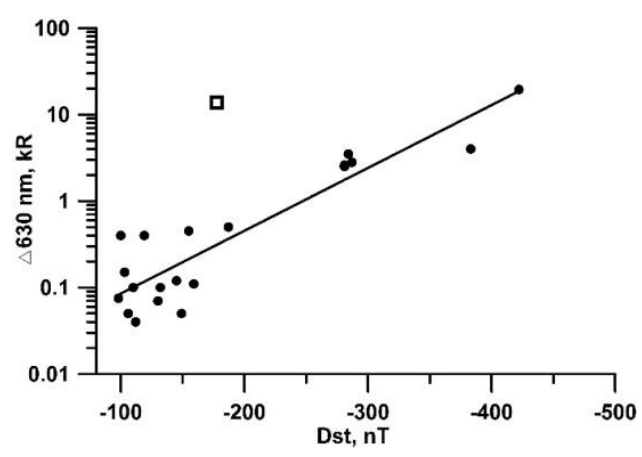

Figure 4. Maximum increase in the mid-latitude $630.0 \mathrm{~nm}$ emission intensity versus geomagnetic activity level (according to Dst)

particular, events of quasi-synchronous increases in $I_{557.7}$ and $I_{630.0}$ were observed when the F2-layer peak height decreased [Leonovich et al., 2012]. During severe MSs when in addition to the main mechanism of $I_{630.0}$ excitation it is excited by particle precipitation, the relationship between the emission intensity and ionospheric parameters is different (see, e.g., results of MA recording at GPhO during the April 6, 2000 MS [Afraimovich et al., 2002]).

The $557.7 \mathrm{~nm}[\mathrm{OI}]$ emission at middle latitudes during MS. The ratio $I_{630.0} / I_{557.7}$ and types of aurora

It is known that during magnetic storms aurora shifts to middle latitudes synchronously with the motion of boundaries of ionospheric and magnetospheric structures (see, e.g., [Lazutin, 2015] and references therein). Equatorward of the auroral oval there is an extended area of airglow called diffuse aurora [Zverev et al., 2012]. Unlike the common discrete aurora, the 557.7 $\mathrm{nm}[\mathrm{OI}]$ emission is not dominant in MA and diffuse aurora [Rassoul et al., 1993; Zverev et al., 2012]. Meanwhile, some papers report results of observation of enhancement of this emission during MS and discuss possible mechanisms (see, e.g., [Shiokawa et al., 2005]). According to $\mathrm{GPhO}$ data, the $I_{557.7}$ enhancement has been observed many times during severe MSs both in the main phase [Mikhalev, 2001; Mikhalev et al., 2004] and in the recovery phase [Degtyarev et al., 2003]. The most intense perturbations of $I_{557.7}$ occurred during March 31, 2001, October 30 and November 20, 2003 severe MSs when the intensity of this emission in individual intervals was as high as $\sim 1-10 \mathrm{kR}$. Sudden and significant enhancements of $I_{557.7}$ at the GPhO latitude may be associated with increasing precipitating energetic neutral atom fluxes from the developed ring current [Tinsley et al., 1984], with the local current system of magnetospheric substorm [Mishin et al., 2018], or with processes of substorm active phase, which lead to expansion of the oval in the equatorial direction to middle and low latitudes with possible precipitation of auroral energy electrons. The sharp increase in the $557.7 \mathrm{~nm}$ emission at middle latitudes during MSs is likely to indicate common aurora.

The ratio of red and green oxygen emission intensities $I_{630.0} / I_{557.7}$ is often used to estimate the energy of precipitating particles and to identify the type of aurora. For the common aurora at heights below $150 \mathrm{~km}$, $I_{630.0} / I_{557.7}$ is usually within $\sim 0.2-1$ [Omholt, 1974]. The ratio of emission intensities $I_{630.0} / I_{557.7}$ in diffuse aurora is 2-4 [Zverev et al., 2012] for precipitating electron energies from $200 \mathrm{eV}$ [Bame et al., 1967] to $1 \mathrm{keV}$ and more [Khorosheva, 1987; Simmons, 1998]. For the type «d» MA (according to the color classification - red aurora), the ratio $I_{630.0} / I_{557.7}$ is $1-10(\sim 10-1000 \mathrm{eV}$ electrons); and for SAR arcs, over $10(\sim 10 \mathrm{eV}$ electrons) [Rassoul et al., 1993]. Figure 5 shows $I_{630.0} / I_{557.7}$ variations for some MSs under study.

The diffuse aurora is formed due to direct invasion of plasma sheet electrons, which without acceleration precipitate into the upper atmosphere. In the evening sector, 

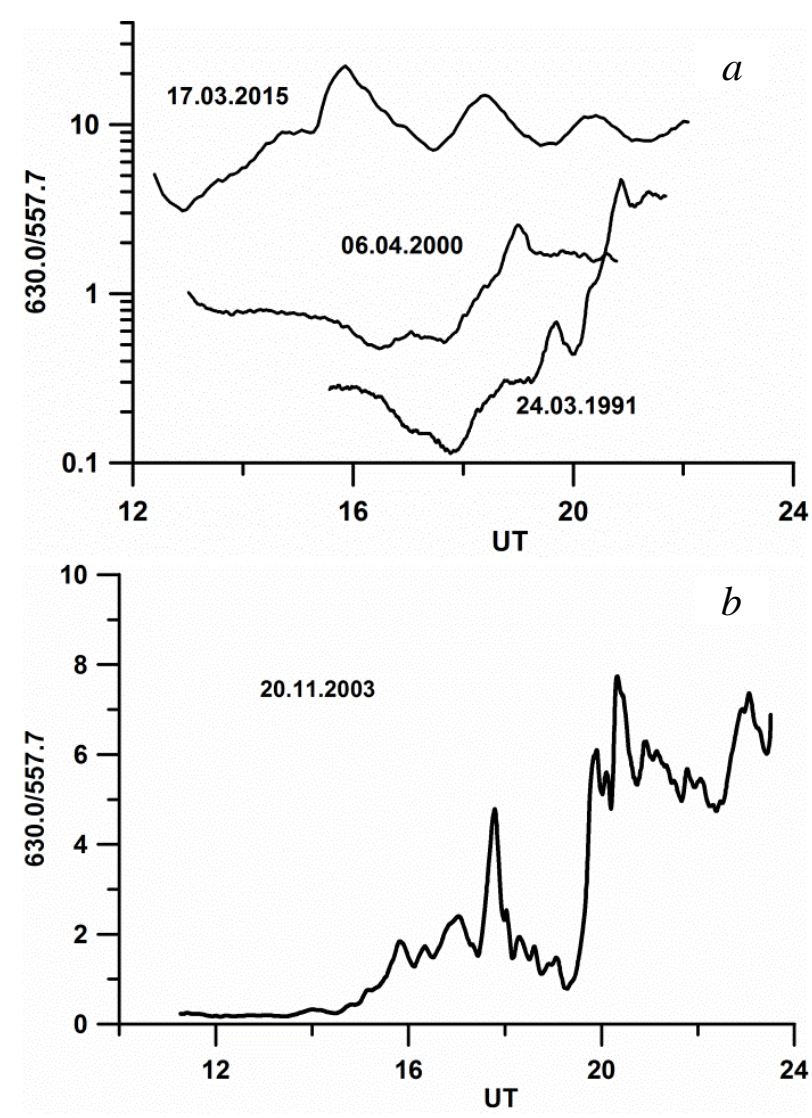

Figure 5. Variations in the $I_{630.0} / I_{557.7}$ ratio for the March 24, 1991, April 6, 2000, March 17, 2015 magnetic storms (a) and the November 20, 2003 magnetic superstorm $(b)$

the diffuse aurora is caused by soft electrons. During morning hours there is a more complex structure of the diffuse aurora. During magnetospheric disturbances, energetic electrons drift from the night side to the day side [Starkov, 2000]. The diffuse aurora region coincides spatially with the region of precipitation of soft electrons extending equatorward from the boundary of the oval to the latitude of plasmapause projection along magnetic field lines on the ionosphere [Fairfield, Vinos, 1984; Zverev et al., 2012], whereas the type «d» MA, as well as SAR arcs, are associated with the plasmapause projection.

According to [Galperin et al., 1977; Fairfield, Vinos, 1984; Khorosheva, 1987], the low-latitude boundary of diffuse precipitation defines the inner boundary of the plasma sheet, and during substorms, moving deep into the magnetosphere, it can reach the plasmapause.

Presumably, this situation is realized mainly during strong MSs, which are discussed in this paper. In this case, we can assume that the diffuse aurora having a projection on the inner boundary of the plasma sheet, and type «d» aurora associated with plasmapause [Rassoul et al., 1993], can be observed (probably at different heights due to different energies of precipitating electrons) simultaneously, forming aurora of mixed type consisting of diffuse aurora and altitude red aurora of type «d».

Since the diffuse aurora and the altitude red aurora have some similar characteristics such as the large ratio $I_{630.0} / I_{557.7}$ and the diffuse aurora, their identification in certain intervals may be difficult. Noteworthy in this respect is the behavior of $I_{630.0} / I_{557.7}$ during the November 20, 2003 MS (Figure 5). During the MS main phase between 16 and 19 UT, this ratio varied from 1.5 to 4 (which is typical both of the diffuse aurora and of the type «d» aurora), and between 20 and 23 UT during the transition to the MS recovery phase when the $557.7 \mathrm{~nm}$ emission intensity sharply decreased almost to the prestorm level the $I_{630.0} / I_{557.7}$ ratio increased to 5-7. If we try to associate this abrupt change in $I_{630.0} / I_{557.7}$ with the motion of magnetospheric structures, changes in $I_{630.0} / I_{557.7}$ until 19 UT can probably be attributed to the projection of the plasma sheet inner boundary $(\sim 1 \mathrm{keV}$ electrons); and the increased $I_{630.0} / I_{557.7}$ ratio after $19 \mathrm{UT}$, to the plasmapause projection, the region with softer electrons $(\sim 10-1000 \mathrm{eV})$.

Mishin et al. [2018] have used the $I_{630.0} / I_{557.7}$ ratio for the November 20, 2003 storm to estimate the energy of precipitating electrons, which was $<0.3 \mathrm{keV}$. The obtained precipitating electron energy of $<0.3 \mathrm{keV}$, according to the classification [Rassoul et al., 1993], may point to the realization of the mid-latitude type «d» aurora.

\section{Emissions [NI] and $\mathrm{N}_{2}$ (1NG) at middle lati- tudes during MSs}

In the MA emission spectrum, in addition to the dominant auroral emissions at 557.7 and $630.0 \mathrm{~nm}$ also typical of the mid-latitude atmospheric emission there is an enhancement or occurrence of emissions abnormal for middle latitudes such as the $520 \mathrm{~nm}$ atomic nitrogen [NI] emission and $\mathrm{N}_{2}^{+}$(1NG) bands [Rassoul et al., 1993].

The $520 \mathrm{~nm}[\mathrm{NI}]$ emission (doublet 519.85 and $520.07 \mathrm{~nm}[\mathrm{NI}]_{21}$ ), according to [Chamberlan, 1961], often appears as a moderately intense line in auroral spectra observed at low latitudes. Excitation potential for this emission is several $\mathrm{eV}$, which may imply corresponding electron energies or population of electrons with a temperature of $k T \sim 1 \mathrm{eV}$.

The $\mathrm{N}_{2}^{+}(1 \mathrm{NG})$ bands are observed in the common aurora when molecular nitrogen is ionized due to precipitation of auroral energy electrons [Omholt, 1974]. In MA, they are also associated with excitation of nitrogen molecules by energetic $(\sim 1-100 \mathrm{keV})$ heavy particles (neutrals) at geomagnetic latitudes of $\leq 40^{\circ}$ and/or by ions at geomagnetic latitudes of $\geq 40^{\circ}$ precipitating from the developed ring current [Rassoul et al., 1993]. Note that in the diffuse aurora there is practically no aurora in the $\mathrm{N}_{2}^{+}$(1NG) bands [Starkov, 2000]. At the same time, some MSs analyzed in this paper also exhibit the 520 $\mathrm{nm}$ [NI] emission (on September 26, 2011 and March $17,2015)$ and the 391.4 and $586.7 \mathrm{~nm} \mathrm{~N}_{2}{ }^{+}(1 \mathrm{NG})$ bands (on November 20, 2003 and March 17, 2015) [Mikhalev et al., 2004, 2018; Mishin et al., 2018].

Noteworthy is an interesting feature, observed in [Shuiskaya, 1970], in red aurora at middle latitudes during strong and very strong storms in 1957-1959, which may be helpful in determining the type of aurora. In almost all the cases, such long-lived aurora had 3-10 min micropulsations in the horizontal component of the magnetic field. The November 20, 2003 MS had also magnetic pulsations with these periods from $\sim 16$ to 20 UT 
when $I_{630.0} / I_{557.7}$ was within $1.5-4$, and had virtually no pulsations after $20 \mathrm{UT}$ when $I_{630.0} / I_{557.7}$ increased to $5-7$ [Mishin et al., 2018].

The relationship of the $630.0 \mathrm{~nm}$ emission intensity with Dst during MSs leads to the following conclusion regarding the November 20, 2003 MA. The minimum value of $D s t=-465$ nT during the November 20, 2003 MS can be classified as extreme for the entire period of instrumental observations. From 1957 to 2012, only one MS (March 13-14, 1989) had lower Dst. The February 11, 1958 geomagnetic storm, which was accompanied by the famous planetary MA, had minimum Dst $=-426 \mathrm{nT}$. The maximum values of $I_{630.0}$ during the November 20, 2003 MS are the highest for the entire period of the optical observations at ISTP SB RAS GPhO. This also applies to the $557.7 \mathrm{~nm}$ emission perturbation, recorded during the November 20, 2003 MA. This MA can probably extend the list of great aurora discussed in a number of papers [Vallance Jones, 1992].

\section{SAR arcs}

According to the classification [Rassoul et al., 1993], SAR arcs are classed with mid-latitude aurora. It has been established [Cole, 1970; Kozyra et al., 1997] that SAR arcs along magnetic field lines are adjacent to the region of interaction between ring current hot particles and the cold external plasmasphere, and most likely represent the radial gradient of the cold plasma density, where plasmaspheric electrons are heated by ring current energetic ions [Ievenko Alexeyev, 2004]. Notice that SAR arcs are often associated with the plasmapause projection and hence with the equatorial wall of the main ionospheric trough [Khorosheva, 1987]. A direct source of $630.0 \mathrm{~nm}$ emission excitation $\left({ }^{1} \mathrm{D}\right.$ level) is considered to be electrons with energies below 10 eV [Rassoul et al., 1993].

As derived from GPhO observations, only four events have been classed with SAR arcs: March 25, 1991, April 7, 2000, March 31, 2001 [Mikhalev et al., 2005], and March 17, 2015 [Mikhalev et al., 2018].

Figure 6 shows images in the $630.0 \mathrm{~nm}$ emission taken by the all-sky camera KEO at different times compared to the $630.0 \mathrm{~nm}$ emission dynamics obtained from patrol spectrograph data [Mikhalev et al., 2018]. The recorded SAR arc moved southward with a mean velocity of $\sim 20$ $\mathrm{m} / \mathrm{s}$ (calculated for the height of $\sim 400 \mathrm{~km}$ ). The velocity of the displacement and size of this arc match the parameters of SAR arcs reported in [Ievenko, Alekseev, 2004].

\section{Color and vertical localization of MA}

Red auroras of type «a» or «d» are considered to occur much higher than the common aurora. "Beautiful dark-red structures" are observed at heights 300-400 km [Akasofu, 1966]. Figure 7 displays images of the northern part of the sky obtained from MA observations during the September 26, 2011 and March 17, 2015 MSs at different geomagnetic activity levels. We can observe the presence of extended regions with dominant red shades caused by predominance of the $630.0 \mathrm{~nm}$ atomic oxygen red emission intensity over the total intensity of all other emissions and continuum in the visible spectrum of MA.

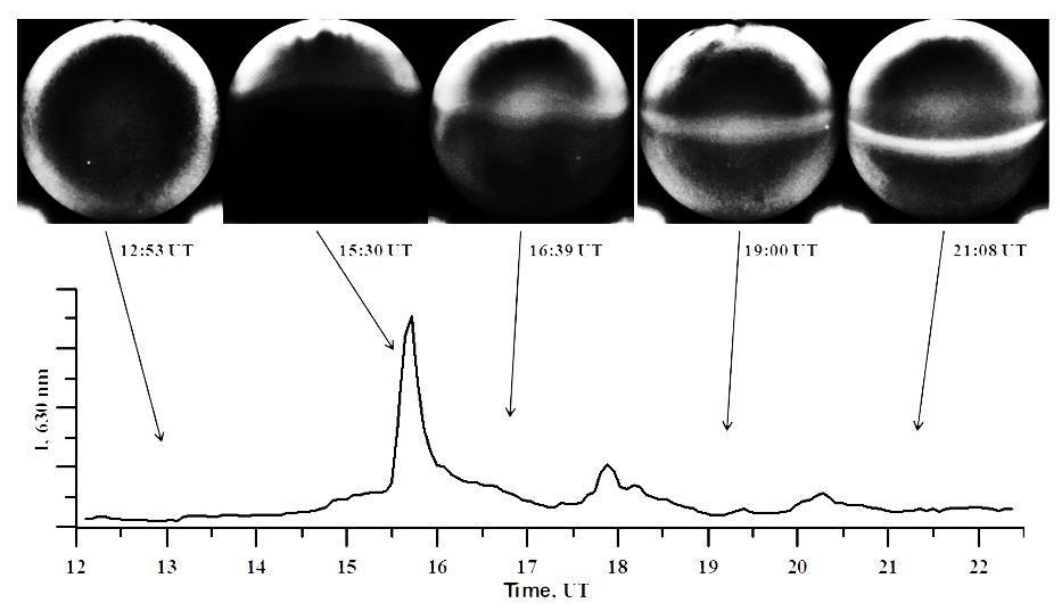

Figure 6. Images in the $630.0 \mathrm{~nm}$ emission taken by the all-sky camera KEO at different times (top) compared to the $630.0 \mathrm{~nm}$ emission dynamics obtained with the patrol spectrograph (bottom) [Mikhalev et al., 2018]
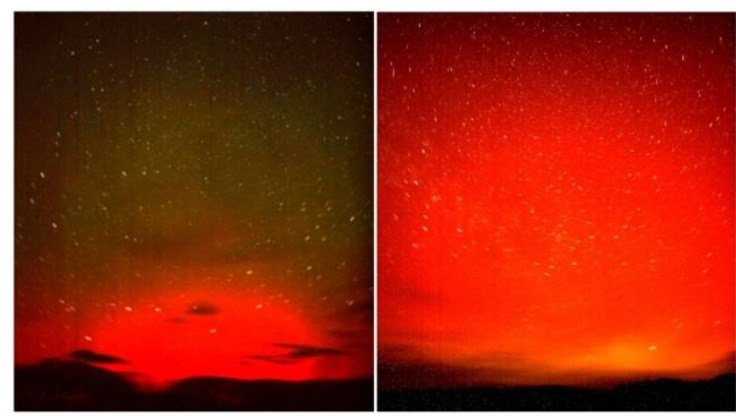

Figure 7. Images of the northern part of the sky captured by the wide-angle color camera Filin-1Ts [http://atmos.iszf.irk.ru/ru/data/color] during two MSs: September 26, 2011, $K_{\mathrm{p}}=6+, D s t_{\min }=-101,16: 48 \mathrm{UT}(a)$; March 17, 2015, $K_{\mathrm{p}}=8-, D s t_{\min }=-222,15: 19$ UT $(b)$ 
Mikhalev et al. [2018] have estimated the vertical distribution of the $630.0 \mathrm{~nm}$ emission for the March 17, 2015 MA, using aspect observations. So, the maximum $630.0 \mathrm{~nm}$ emission was observed at $\sim 200-300 \mathrm{~km}$, and the upper boundary extended to $\sim 350-550 \mathrm{~km}$. The obtained vertical distribution of the $630.0 \mathrm{~nm}$ emission, the predominance of this emission in the observed spectrum, and the diffuse March 17, 2015 MA allow us to assign this aurora to type «d» red auroras according to the color classification. Red color can probably be seen in subvisual aurora of diffuse aurora type too, observed equatorward of the auroral oval, with $630.0 \mathrm{~nm}$ emission peak heights to $320 \mathrm{~km}$ [Zverev et al., 2012].

The color wide-angle camera whose images are shown in Figure 7 was put into operation only in 2009. In this regard, there are, unfortunately, no MA images during the extrastorms of interest (see Table) before this year. This is also the case for the all-sky camera KEO Sentinel, commissioned in 2013 (images in the 630.0 $\mathrm{nm}$ emission obtained with it are shown in Figure 6).

At the same time, in certain short observations (when the $557.7 \mathrm{~nm}$ emission increases) this MA can also be classified as type "a" aurora (red color in the upper part of the aurora and the dominant green color in its lower part).

SAR arcs also feature large emission heights $\sim 400$ $450 \mathrm{~km}$.

It should be noted that for the aurora of types considered (type «d», SAR arcs, diffuse aurora) the large ratio $I_{630.0} / I_{557.7}$ (determining the red aurora) simultaneously with large heights of observation of the aurora indicates relatively low energies of precipitating electrons of $\leq 1 \mathrm{keV}$ [Rees, Luckey, 1974].

\section{CONCLUSIONS}

The results of MA recording in solar cycles 23-24 reported in this paper lead to the preliminary conclusions concerning certain MA characteristics observed in the south of Eastern Siberia near the geomagnetic meridian of $177^{\circ} \mathrm{E}$.

The most intense MA corresponding to the MS main phase is largely recorded in the second half of the night. The main dominant emission in MA is the $630.0 \mathrm{~nm}$ [OI] atomic oxygen emission.

For most MA a relationship is observed between the dominant $630.0 \mathrm{~nm}$ emission intensity and the Dst index. $I_{630.0}$ during superstorms can reach the highest values units-tens of $\mathrm{kR}$ in the MA maximum phase at the developed ring current. The large 630.0 and $557.7 \mathrm{~nm}$ emission intensity ratios observed in MA may indicate that precipitating electrons have low energies. A source of these electrons may be the region of overlapping of the plasmapause with ring current energetic ions (the source of $\leq 10-1000 \mathrm{eV}$ electrons) or the inner boundary of the plasma sheet (the source of $\leq 1 \mathrm{keV}$ electrons), whose projections during intense MSs can shift to middle and low latitudes.

For certain MSs there were also short-term intense perturbations of $I_{557.7}$, at individual intervals $I_{557.7} \sim 1-10$ $\mathrm{kR}$. At the GPhO latitude, such perturbations of $I_{557.7}$ may be caused by an increase in the precipitating energetic neutral particle flux from the developed ring current, equatorward auroral oval extension to middle and low latitudes with possible precipitation of auroral energy electrons during superstorms, or by the local current system of a magnetospheric substorm.

In addition to the 557.7 and $630.0 \mathrm{~nm}$ emissions characteristic of the mid-latitude nightglow spectrum, in MA spectra there are emissions abnormal for middle latitudes such as the $520 \mathrm{~nm}[\mathrm{NI}]$ atomic nitrogen emission and $\mathrm{N}_{2}{ }^{+}(1 \mathrm{NG})$ bands.

As derived from $\mathrm{GPhO}$ observations, only four events have been classed with SAR arcs: March 25, 1991, April 7, 2000, March 31, 2001, and March 17, 2015.

According to the classification of MSs by Dst [Gonzalez et al., 1999], 7 MSs, during which in Eastern Siberia intense MA were recorded, can be classified as extrastorms. The mid-latitude aurora recorded on November 20, 2003 can extend the list of great aurora.

The work was performed with budgetary funding of Basic Research program II.16 (regular optical observation and development of a database from airglow characteristics in solar cycles 23-24) and RFBR grant No. 19-05-00665 (analysis of data on MA and their possible relationship with ionospheric-magnetospheric structures). This work is based on data obtained using the equipment of Center for Common Use «Angara» [http://ckp-rf.ru/ckp/3056].

\section{REFERENCES}

Afraimovich E.L., Yashkaliev Ya.F., Aushev V.M. Beletsky A.B., Vodyanikov V.V., Leonovich L.A., Lesyuta O.S., Mikhalev A.V., Yakovets A.F. Simultaneous radiophysical and optical measurements of the ionospheric response during a major magnetic storm on April 6, 2000. Geomagnetizm i aeronomiya [Geomagnetism and Aeronomy]. 2002, vol. 42, no. 3, pp. 383-393. (In Russian).

Akasofu S. Auroras. Uspehi fizicheskih nauk [Advances in the Physical Sciences]. 1966, vol. 89, no 4, pp. 669-680. (In Russian).

Bame S.J., Asbridgie J.R., Felthauseer H.E., Honesa E.W., Strong I.B. Characteristics of the plasma sheet in the Earth's magnetotail. J. Geophys. Res. 1967, vol. 72, iss. 1, pp. 113-129. DOI: 10.1029/JZ072i001p00113.

Barbier D. Recherches sur la raie 630.0 de la luminescence atmospherique nocturne. Ann. Geophys. 1959, vol. 15, no. 2, pp. 179-217.

Chamberlan J.W. Physics of the Aurora and Airglow. London, Academic Press, 1961, 722 p. (International Geophysics Series, vol. 2).

Cole K.D. Magnetospheric processes leading to midlatitude aurora. Annales de Géophysique. 1970, vol. 26, no. 1, pp. 187-193.

Degtyarev V.I., Mikhalev A.V., Jiyao Xu. Variations of the glow of the night sky in Eastern Siberia in the period of magnetic storm from March 31 to April 4, 2001. Optika atmosfery i okeana [Atmospheric and Oceanic Optics]. 2003, vol. 16, no. 5-6, pp. 552-556. (In Russian).

Fairfield D.H., Vinos A.F. The inner edge of the plasma sheet and the diffuse aurora. J. Geophys. Res. 1984, vol. 89, no. A2, pp. 841-854. DOI: 10.1029/JA089iA02p00841.

Fishkova L.M., Martsvaladze N.M. On the behavior of HI $656.3 \mathrm{~nm}$ and [OI] $630 \mathrm{~nm}$ emissions of the upper atmosphere during magnetic storms with a sudden onset. Geomagnetizm $i$ 
aeronomiya [Geomagnetism and Aeronomy]. 1985, vol. 27, no. 3, pp. 509-511. (In Russian).

Galperin Yu.I., Cranier J., Lisakov Yu.V., Nikolaenko L.M., Sinitsyn V.M., Soveaux J.-A., Khalipov V.L. Model of the equatorward boundary of the auroral electron diffusion precipitation zone in the dusk and nearmidnight sectors. Kosmicheskie issledovaniya [Cosmic Res.]. 1977, vol. 15, no. 3, pp. 421-433. (In Russian).

Gonzalez W.D., Tsurutani B.T., Clúa de Gonzalez A.L. Interplanetary origin of geomagnetic storms. Space Sci. Rev. 1999, vol. 88, iss. 3-4, pp. 529-562. DOI: 10.1023/A: 1005160 129098.

Ievenko I.B., Alekseyev V.N. The influence of the substorm and storm on the dynamics of the SAR arc. Statistical analysis. Geomagnetizm i aeronomiya [Geomagnetism and Aeronomy]. 2004, vol. 44, no. 5, pp. 643-654. (In Russian).

Khorosheva O.V. Magnetospheric disturbances and the associated dynamics of the ionospheric electrojet, auroras and plasmapause. Geomagnetizm i aeronomiya [Geomagnetism and Aeronomy]. 1987, vol. XXVII, no. 5, pp. 804-811. (In Russian).

Kozyra J.U., Nagy A.F., Slater D.W. High-altitude energy source(s) for stable auroral red arcs. Rev. Geophys. 1997, vol. 35, iss. 2, pp. 155-190. DOI: 10.1029/96RG03194.

Krakovetsky Yu.K., Loisha V.A., Popov L.N. Chronology the auroras for last millennium. Solnechnye dannye [Solar Data]. 1989, no. 5, pp. 110-115. (In Russian).

Lazutin L.L. The auroral oval is a beautiful but outdated paradigm. Solnechno-zemnaya fizika [Solar-Terr. Phys.]. 2015, vol. 1, no. 1, pp. 23-35. (In Russian).

Leonovich L.A., Mikhalev A.V., Leonovich V.A. Covariations in atomic oxygen emissions and ionospheric total electron content during geomagnetic storms. J. Atmos. Solar-Terr. Phys. 2012, vol. 80, no. 5, pp. 247-251. DOI: $10.1016 /$ j. jastp.2012.02.003.

Lobzin V.V., Pavlov A.V. The relationship of the intensity of the glow of subauroral red arcs with solar and geomagnetic activity. Geomagnetizm i aeronomiya [Geomagnetism and Aeronomy]. 1998, vol. 38, no. 3, pp. 49-61. (In Russian).

Mikhalev A.V. Some particulars in observation of midlatitude airglows and disturbances of the upper atmosphere emissions during magnetic storms in the Eastern Siberia region. Optika atmosfery i okeana [Atmospheric and Oceanic Optics]. 2001, vol. 14, no. 10, pp. 970-973. (In Russian).

Mikhalev A.V., Beletsky A.B., Kostyleva N.V., Chernigovskaya M.A. Mid-latitude airglows in the southeast Siberia during strong magnetic storms on October 29-31 and November 20-21, 2003. Kosmicheskie issledovaniya [Cosmic Res.]. 2004, vol. 42, no. 6, pp. 616-621. (In Russian).

Mikhalev A.V., Beletsky A.B., Kostyleva N.V., Chernigovskaya M.A. Characteristics of mid-latitude airglows during strong magnetic storms in the current solar cycle. Optika atmosfery i okeana [Atmospheric and Oceanic Optics]. 2005, vol. 18, no. 01-02, pp. 155-159. (In Russian).

Mikhalev A.V. Mid-latitude auroras in Eastern Siberia in 1991-2012. Solnechno-zemnaya fizika [Solar-Terr. Phys.]. 2013, vol. 24, pp.78-83. (In Russian).

Mikhalev A.V., Beletsky A.B., Vasilyev R.V., Zherebtsov G.A., Podlesny S.V., Tashchilin M.A., Artamonov M.F. Spectral and photometric characteristics of mid-latitude auroras during the magnetic storm of March 17, 2015. SolarTerr. Phys. 2018, vol. 4, iss. 4, pp. 42-47. DOI: $10.12737 /$ stp-44201806.

Mishin V.V., Lunyushkin S.B., Mikhalev A.V., Klibanova Yu.Yu., Tsegmed B., Karavaev Yu.A., Tashchilin A.V., Leonovich L.A., Penskikh Yu.V. Extreme geomagnetic and optical disturbances over Irkutsk during the 2003 November 20 superstorm. J. Atmos. Solar-Terr. Phys. 2018, vol. 181, pt. A, pp. 68-78. DOI: 10.1016/j.jastp.2018.10.013.
Nadubovich Yu.A. Morfologicheskie issledovaniya polyarnykh siyaii [Morphological Studies of Auroras]. Novosibirsk, Nauka Publ., 1992, 384 p.

Omholt A. Polyarnye siyaniya [Auroras]. Moscow, Mir Publ., 1974, 246 p. (In Russian). (English edition: Omholt A. The Optical Aurora. Springer-Verlag Berlin - Heidelberg, 1971, 200 p. DOI: 10.1007/978-3-642-46269-6.)

Rassoul H.K., Rohrbaugh R.P., Tinsley B.A. Low-latitude particle precipitation and associated local magnetic disturbance. J. Geophys. Res. 1992. vol. 97, iss. A4, pp. 4041-4052. DOI: 10.1029/91JA03028.

Rassoul H.K., Rohrbaugh R.P., Tinsley B.A., Slater D.W. Spectrometric and photometric observations of low-latitude aurorae. J. Geophys. Res. 1993, vol. 98, iss. A5, pp. 76957709. DOI: $10.1029 / 92 J A 02269$.

Rees M.H., Luckey D. Auroral electron energy derived from ratio of spectroscopic emissions. 1. Model computations. J. Geophys. Res. 1974, vol. 79, iss. 34, pp. 5181-5186. DOI: 10.1029/JA079i034p05181.

Simmons D.A.R. A classification of auroral type. J. Br. Astron. Assoc. 1998, vol. 108, no. 5, pp. 247-257.

Shiokawa K., Ogawa T., Kamide Y. Low-latitude auroras observed in Japan: 1999-2004. J. Geophys. Res. 2005, vol. 110, iss. A5, A05202. DOI: 10.1029/2004JA010706.

Shuiskaya F.K. "Red auroras" at mid-latitudes. Polyarnye siyaniya i svecheniya nochnogo neba [Auroras and Night Airglows]. Moscow, Nauka Publ., 1970, no. 18, pp. 97-103. (In Russian).

Starkov G.V. Planetarnaya dinamika avroral'nogo svecheniya. Fizika okolozemnogo kosmicheskogo prostranstva [Planetary Dynamics of Auroral Luminescence. Physics of Near-Earth Space], vol. 1. Apatity: Izd-vo Kol'skogo nauchnogo tsentra RAN, 2000, 706 p. (In Russian).

Tinsley B.A., Rohrbaugh R.P., Rassoul H., Barker E.S., Cochran A.L., Cochran W.D., Wills B.J., Wills D.W., Slater D. Spectral characteristics of two types of low latitude aurorae. Geophys. Res. Lett. 1984, vol. 11, iss. 6, pp. 572-575. DOI: 10.1029/GL011i006p00572.

Tinsley B.A., Rohrbaugh R.P., Rassoul H., Sahai Y., Teixeira N.R., Slater D. Low-latitude aurorae and storm time current systems. J. Geophys. Res. 1986, vol. 91, iss. A10, pp. 11257-11269. DOI: 10.1029/JA091iA10p11257.

Truttse Yu.L. Upper atmosphere during geomagnetic disturbances. Polyarnye siyaniya $i$ svecheniya nochnogo neba [Auroras and Night Airglows]. 1973, vol. 20, pp. 522. (In Russian).

Vallance Jones A. Historical review of great aurora. Can. J. Phys. 1992, vol. 70, iss. 7, pp. 479-487. DOI : 10.1139/p92-083.

Zverev V.L., Feldshtein Ya.I., Vorobjev V.G. Auroral glow to the equator from the auroral oval. Geomagnetizm $i$ aeronomiya [Geomagnetism and Aeronomy]. 2012, vol. 52, no. 1, pp. 64-72. (In Russian). 2019).

URL: http://atmos.iszf.irk.ru/ru/data/spectr (accessed 20 June 2019).

URL: http://atmos.iszf.irk.ru/ru/data/color (accessed 20 June

URL: http://atmos.iszf.irk.ru/ru/data/keo (accessed 20 June 2019).

URL: http://ckp-rf.ru/ckp/3056 (accessed 20 June 2019).

How to cite this article

Mikhalev A. V. Mid-latitude aurora in solar cycles 23-24 from observations in the south of Eastern Siberia. Solar-Terrestrial Physics. 2019. Vol. 5. Iss. 4. P. 66-73. DOI: 10.12737/stp-54201909. 